\title{
Hydrodynamic Equilibrium for Sediment Transport and Bed Response to Wave Motion
}

\author{
Leszek M. KACZMAREK ${ }^{1}$, Szymon SAWCZYŃSKI ${ }^{2}$, \\ and Jarosław BIEGOWSKI ${ }^{3}$ \\ ${ }^{1}$ University of Technology, Department of Geotechnics, Koszalin, Poland \\ e-mail: leszek.kaczmarek@tu.koszalin.pl \\ ${ }^{2}$ University of Warmia and Mazury, Department of Mechanics \\ and Civil Engineering Constructions, Olsztyn, Poland \\ e-mail: sz.sawczynski@uwm.edu.pl (corresponding author) \\ ${ }^{3}$ Polish Academy of Sciences, Institute of Hydroengineering, Gdańsk, Poland \\ e-mail: jarbieg@ibwpan.gda.pl
}

\begin{abstract}
An experimental and theoretical identification of hydrodynamic equilibrium for sediment transport and bed response to wave motion are considered. The comparison between calculations and the results of laboratory experiments indicates the linear relation between sediment transport rate and the thickness $z_{m}$ of bed layer in which sediments are in apparent rectilinear motion. This linear relationship allows to use the first order "upwind" numerical scheme of FDM ensuring an accurate solution of equation for changes in bed morphology. However, it is necessary to carry out a decomposition of the sediment transport into transport in onshore direction during wave crest and offshore direction during wave trough. Further, the shape of bed erosion in response to sediment transport coincides with the trapezoid envelope or with part of it, when some sediments still remain within it. Bed erosion area is equal to the one of a rectangle with thickness $z_{m}$.
\end{abstract}

Key words: hydrodynamic equilibrium, linear equation of morphological changes, thickness of eroded/accumulated sediment, sand trap. 


\section{INTRODUCTION}

In the coastal zone there is a strong impact of waves and currents on the bed resulting in almost permanent movement of sediment closely related to the variability of bed shape. The importance of the sediment movement within the coastal areas emphasizes the need for mathematical description of sediment transport and bed morphology. Cyclic erosion and accumulation processes, due to the volume of transported sediment, induce dynamic equilibrium of the local seabed. Thus, to describe the bed morphology changes, it is possible to use conservation laws concerning transport of sediments and to use numeric models in order to determine the prediction of changes in the spatial variation of sediment transport within the coastal zone. Hence, morphological models of the coastal zone are essential to predict changes in bathymetry within the coastal zone. They also allow for the analysis of changes in bed elevations in areas in the vicinity of hydraulic structures at the stage of design, construction and use.

Changes in the elevation of the bottom level can be determined by the solutions of the commonly used equation of conservation of mass (Exner equation, e.g., Yalin and da Silva 2001) for bed sediment transport. For the one-dimensional case this can be written as follows:

$$
\frac{\partial z_{b}}{\partial t}+\frac{1}{1-n_{p}} \frac{\partial q_{(x)}}{\partial x}=0
$$

where $z_{b}$ is the bed level elevation [m], $x$ is a horizontal coordinate [m], $t$ is time [s], $n_{p}$ is the sediment porosity [-], and $q_{(x)}$ is the sediment transport rate $\left[\mathrm{m}^{2} / \mathrm{s}\right]$ towards $x$.

To solve Eq. 1 it is required to use various numeric schemes (Callaghan et al. 2006, Chiang and Hsiao 2011, Johnson and Zyserman 2002, Long et al. 2008). As shown, among others by Johnson and Zyserman (2002), the numerical schemes used to solve Eq. 1 generate spatial numerical oscillations. These oscillations of morphological models appear as a result of nonlinear relation between sediment transport rate $q_{(x)}$ and the elevation of the bed level $z_{b}$. The sediment transport rate is also determined on the basis of non-linear, complex hydrodynamic relations. These non-linear relations and numerical errors of the particular sub-models can generate instability and uncertainty of the results of calculation, especially because the nature of these relations is still poorly understood. These models are therefore unable to carry out the exact (physical) prediction of bathymetry in coastal areas, especially in long-term simulations (Johnson and Zyserman 2002).

Over the last few decades, a few techniques, that should improve the stability and accuracy of solutions incorporated into models of bathymetric changes, have been proposed. As shown by Long et al. (2008), many of the 
latest calculation models contain numerical paradigms which smoothen oscillations between results describing the evolution of the seabed morphology. In order to ensure adequate, long-term simulation of bathymetric changes caused by interactions between waves and currents near the seashore, a calculation model should enable to control spatial oscillations and guarantee the accuracy of results. Simultaneously, it should reflect the physical aspects of these changes.

In recent years, several morphological models have been verified with respect to the control of oscillations. Callaghan et al. (2006) reviewed a few numerical schemes and concluded that the Lax-Wendroff's schemes and all their subsequent modifications are unstable with respect to long-term simulated bathymetric changes. It is therefore necessary to expand these schemes, for example by adding such information as artificial viscosity, which will prevent numerical oscillations generated by these methods. Besides, Callaghan et al. (2006) emphasized the difficulties with describing the bed form propagation phase speed as a vital parameter responsible for the stability of the reviewed numerical schemes.

The stability of numerical schemes is typically referred to the requirement concerning the Courant number condition: $C_{r}=C_{a} \Delta t / \Delta x \leq 1$, where $C_{a}$ stands for the bed form propagation phase speed. Thus, it is possible to improve the stability of numerical models by shortening the duration of simulation. It will, however, demand a greater computational power of computers. If the diffusion term is correctly removed from the transport equation, the boundary value of the Courant number can be exceeded (Chiang and Hsiao 2011). This is attainable through the introduction of diffusion constants, which are chosen according to the actual environmental conditions (Cayocca 2001, Chiang et al. 2010, Kuroiwa et al. 2004, Struiksma et al. 1985, Watanabe 1988).

In the authors' approach, it is assumed that due to the shear stress impact on the bottom, the sediment is pulled off directly from the bottom, which is understood as an averaged response of the bed to the particular hydrodynamic conditions in time $\Delta t$ and from the area with a length $\Delta x$. The entire sediment moving in saltation motion above the bottom originates exclusively from the bottom (e.g., Bialik 2013, Moreno and Bombardelli 2012). In hydrodynamic equilibrium conditions, the stream of sediments picked up from the bed with a length $\Delta x$, averaged in time $\Delta t$, is equal (at each level) to the stream of sediments falling onto the bed. No restrictions are imposed on both $\Delta x$ and $\Delta t$ values. The only requirement is that the sediment stream $q_{x}$ passing through the selected profile (1-1 in Fig. 1a) has a constant value. The sediments have been picked up from the bed with a length $\Delta x$, over the time $\Delta t$ before they pass through the selected profile. Usually, the $\Delta x$ value is of 


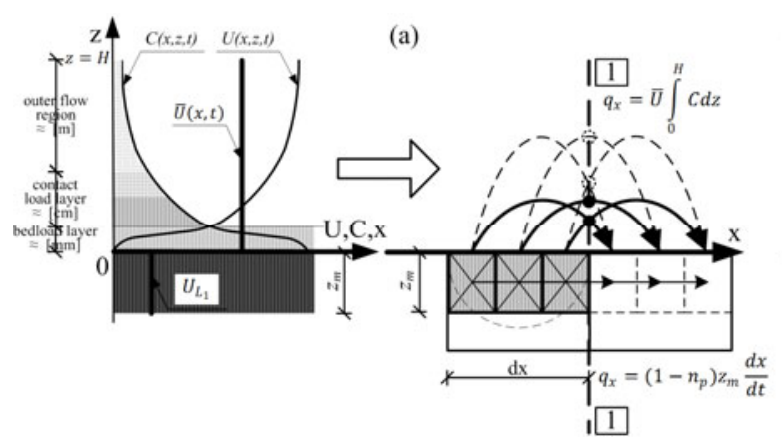

(b)
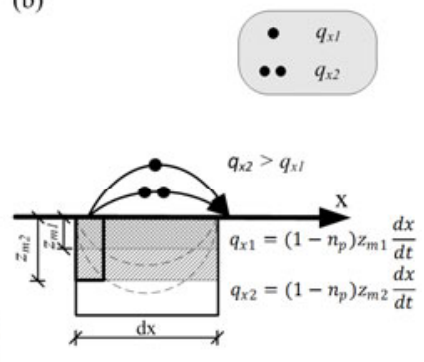

Fig. 1. Scheme of the sediment transport in hydrodynamic equilibrium conditions: (a) sediment stream passing through the 1-1 profile and equilibrium between sediment transport in the bed layer of the thickness $z_{m}$ and the one above the bottom, and (b) the saltation impulse of sediment grains resulting in transport $q_{x 2}>q_{x 1}$ and causing bed erosion of the thickness $z_{m 2}>z_{m 1}$.

the order of $0.05-0.10 \mathrm{~m}$ in numerical modelling against laboratory experiments (e.g., van Rijn et al. 2005, Walstra et al. 2005), while 5-10 m in numerical modelling versus field measurements (e.g., Kaczmarek et al. 2004).

The time $\Delta t$ is expected to be correlated with the duration of an erosion process from the bed with a length $\Delta x$ caused by sediment transport $q_{x}$ passing through the vertical profile (Fig. 1). It is postulated (see Kaczmarek et al. 2004) that erosion depth $z_{\max }$ should not exceed the value of $0.015-0.030 \mathrm{~m}$ in order to satisfy the requirement that the sediment transport has a constant value in time $\Delta t$. This means that the time interval $\Delta t$ can attain relatively great value when the erosion process caused by sediment transport is not intensive.

\section{FORMULA FOR THE PROBLEM}

\subsection{Theoretical background}

The movement of the sediment in the layer above the bottom with the average speed of

$$
\bar{U}=\frac{\int_{0}^{H} U C d z}{\int_{0}^{H} C d z}
$$

implies a kind of sediment apparent rectilinear motion which takes place in the bed, in the layer with the thickness $z_{m}$ (Fig. 1). Wherein $H$ determines water depth, $C$ is the volumetric concentration, averaged in time $d t$, and $U$ means the sediment velocity, averaged in time $d t$. The thickness $z_{m}$ means a thickness of $z_{m} \times d x \times 1$ cell, which is eroded in time $d t$ as a result of the 
transport $q_{x}$ of sediments passing thorough the transverse profile. This thickness is described by the following relation:

$$
z_{m}=\frac{1}{\left(1-n_{p}\right)} \frac{q_{x} d t}{d x}
$$

where $q_{x}$ means the sediment transport rate in the conditions of hydrodynamic equilibrium, while $n_{p}$ is the porosity of sediments.

Cell erosion of the thickness $z_{m}$ proceeds at the forward speed of $U_{L_{1}}$ :

$$
U_{L_{1}}=\frac{d x}{d t},
$$

while

$$
\frac{\bar{U}}{U_{L_{1}}}=\kappa
$$

Conditions of the hydrodynamic equilibrium assume that sediment transport rate $q_{x}$ which takes place in the bed layer of the thickness $z_{m}$ and which results from Eq. 3 in traditional (e.g., van Rijn 1984) form:

$$
q_{x}=\left(1-n_{p}\right) U_{L_{1}} z_{m}
$$

is equal to the sediment transport above the bottom (Fig. 1). The sediment transport above the bed is described by the following relation:

$$
q_{x}=\bar{U} \int_{0}^{H} C d z=U_{L_{1}} \kappa \int_{0}^{H} C d z
$$

from which one can obtain:

$$
\left(1-n_{p}\right) z_{m}=\kappa \int_{0}^{H} C d z
$$

The essential role in initiating the motion of sediment is performed by grain saltation (e.g., Bialik and Czernuszenko 2013, Bialik et al. 2012, Wiberg and Smith 1985) (Fig. 1a). Figure 1a shows that a saltation impulse moves a total number of sediment grains in a jump over the length $d x$. Thus, the saltation impulse (Fig. 1b) of sediment grains resulting in transport $q_{x 2}>q_{x 1}$ causes in time $d t$ the erosion of the seabed of the thickness $z_{m 2}>z_{m 1}$, in a cell of the length $d x$. This means that under the hydrodynamic equilibrium the thickness $z_{m}$ is a function of the sediment transport rate whereas forward speed $U_{L_{1}}$, described by Eq. 4, does not depend on the said rate. In other words, under hydrodynamic equilibrium condition, the sediment transport above the bed is equal to the one inside the bed for any length 
$d x$ and time $d t$ as long as the forward speed $U_{L_{1}}$ does not depend on sediment transport rate $q_{x}$ and coordinate $x$. Consequently, a grain jump above the bottom with any trajectory height, which corresponds to an apparent stroke of a layer inside the bed, is defined by Eq. 7 also for any length $d x$ and time $d t$. The only requirement is that the sediment transport has a constant value in time $d t$ and along the entire length $d x$.

These conclusions coincide with what Einstein proposed in 1950. Based on experimental observations, Einstein (1950) assumed that the averaged distance travelled by a sand particle between erosion and subsequent deposition, is simply proportional to the grain diameter and independent of the hydraulic conditions and the amount of sediment in motion. It means that every jump of any length is equally probable at every $x$ point. As a result, any $x$ point is the origin of different jumps, altogether resulting in sediment transport $q_{x}$. In that case, the stream of sediments picked up in time $d t$ from every $x$ point along the distance $d x$ is equal to the stream of sediments following onto the bed. Figure 1 shows the simplified case, when all considered jumps are defined by one particular length. In addition, for any value of $d x$, the saltation motion of sediment grains with the transport rate of, respectively, $q_{x 1}$ and $q_{x 2}$ will trigger (after the sufficiently long times $t_{2}$ and $t_{1}$ ) the erosion of the bed with the same thickness $z_{\max }$, so from Eq. 3 it results that:

$$
q_{x 2} t_{2}=q_{x 1} t_{1}=\left(1-n_{p}\right) z_{\max } d x .
$$

The thickness $z_{\max }$ is therefore also the value which is independent of the sediment transport rate $q_{x}$ and it should be determined on the basis of experiments.

A good empirical illustration of a motion of sediment under the hydrodynamic equilibrium is the flow of water over a box filled with sediment (Fig. 1). If the bottom outside the box is made of concrete, then it is not difficult to image that all the sediment moving above the bottom originates from that bed structure. It can be assumed that under determined water flow conditions, the erosion of sediments from the box (Fig. 1a) is caused by the simultaneous (along the entire length $d x$ ) grain strokes with the length $d x$ and with the total size $z_{m}$ or by corresponding to them grain jumps with any trajectory height. In such a case, the bottom sediment erosion is constant at the entire $d x$ length and it amounts to $z_{m}$ (Fig. 1).

This picture is not exclusively approximated by situation with jumps defined by one particular length $d x$. It is also simplified because of the fact that the material is transported from the central part of the $d x$ area and from only one extreme area (Fig. 1a) at any moment and for every height of jump trajectory. Indeed, the erosion of the bed is not constant over the entire $d x$ length. The middle part is eroded twice strongly than extreme areas. It is 
postulated, however, that the actual size of the bed erosion - in the entire area of $d x$ - is equal to the value calculated assuming a constant erosion along $d x$.

\subsection{Scope of the work}

The main aim of this study is to demonstrate (on the basis of the results obtained from laboratory experiments of "IBW PAN 1996" (Kaczmarek 1999) and "IBW PAN 2010" (Sawczyński 2012)) the postulate of sediment transport in hydrodynamic equilibrium conditions. Measurements were carried out in the wave flume of the Institute of Hydroengineering, Polish Academy of Sciences (IBW PAN) in Gdańsk in 2010 (Sawczyński 2012). The aim of the experiment was to make measurements of the thickness of eroded bed sediment $\left(z_{m}\right)_{e}$ in the context of comparative analysis of the results of "IBW PAN 1996" experiment, during which the measurements of cumulative thickness $\left(z_{m}\right)_{a}$ were carried out (Kaczmarek 1999). Within the frame of the study, two tests, T4 and T5, were performed for the eroded thickness of the sediment. The laboratory experiments $\mathrm{T} 4$ and $\mathrm{T} 5$ indicate that the bathymetry of erosion area coincides with the trapezoid envelope or with a part of it, when a part of sediments still remains within it. In both cases the erosion area is equal to the rectangle one with thickness $\left(z_{m}\right)_{e}$ along the entire length $d x$.

The results of the measurements are to be used as a confirmation of the hypothesis of hydrodynamic equilibrium, i.e., the possibility to adopt the linear relation 6 between the sediment transport rate $q_{x}$ and thickness $z_{m}$ of a bed layer where densely packed grains of the sediment participate in the apparent translational and rectilinear motion. This motion is caused by the actual sediment grain flow over the bed, in the form of steps. This linear relationship 6 gives the opportunity to use a numerical scheme of the first order "upwind" the finite difference method (FDM). This method provides an accurate solution of the equation describing the changes in bathymetry in time and space (Kaczmarek et al. 2011, Sawczyński 2012):

$$
\frac{\partial z_{m}}{\partial t}+\frac{1}{1-n_{p}} \frac{\partial q_{x}}{\partial x}=0 \text {. }
$$

At the same time, the following relation is valid:

$$
z_{b}(x, t+d t)=z_{b}(x, t)+\frac{\partial z_{m}}{\partial t} d t .
$$

Thus, as long as the sediment transport remains in the hydrodynamic equilibrium conditions, the first order "upwind" numerical scheme of FDM can be used to obtain an accurate solution of Eq. 10. However, as it is shown 
in Section 3, the decomposition of the sediment transport into the one in onshore direction during wave crest and offshore direction during wave trough should be done.

In contrast to the proposal described above, numerical schemes based on non-linear relation between the sediment transport rate $q_{x}$ and the elevation of the bed level $z_{b}$, used in Eq. 1 to describe changes in bathymetry, are unstable ones and generate oscillations in calculation results. It was shown inter alia by Sawczyński (2012) and Szymkiewicz (1999).

It should be emphasized that the postulate of the linear relationship 4 between sediment transport rate $q_{x}$ and the thickness $z_{m}$ of layer in apparent motion does not correspond to the postulate of a linear relationship between the sediment transport rate $q_{x}$ and the elevation of the bed level $z_{b}$. The last relationship is still postulated as non-linear.

\section{SEDIMENT TRANSPORT IN THE WAVE MOTION}

The instantaneous velocities $u$ and sediment concentrations $c$ in water flow under surface waves can be written in the following form:

$$
\begin{aligned}
& u=\langle U\rangle+\tilde{U}, \\
& c=\langle C\rangle+\tilde{C},
\end{aligned}
$$

where $\langle\ldots\rangle=\frac{1}{T} \int_{0}^{T}(\ldots) d t$ means the averaged value in time of the wave pe$\operatorname{riod}(T)$, while $\tilde{U}$ and $\tilde{C}$ are the oscillating components of the velocity and concentration, respectively.

The product of velocity and concentration is defined as the volumetric stream related to the unitary area presented as follows:

$$
\langle\phi\rangle=\langle U\rangle\langle C\rangle+\langle\tilde{U} \tilde{C}\rangle=U_{L}\langle C\rangle .
$$

The velocity $U_{L}$, according to Plumb's (1979) study, is a kind of Lagrange's speed similarly to forward speed $U_{L_{1}}$ of the bed layer with the thickness $z_{m}$, as determined by Eq. 3 .

It is postulated to implement the decomposition of the sediment flow induced by waves into ones during wave crest $\left(T_{c}\right)$ and wave trough $\left(T_{t}\right)$, respectively. Consequently:

$$
T=T_{C}+T_{t} .
$$

The parameters related to the wave crest and wave trough are marked as $\left.(\ldots)^{+}\right)$and $(\ldots)$, respectively. Thus, the volumetric stream may be presented in the following form: 


$$
\langle\phi\rangle=\left\langle\phi^{+}+\phi^{-}\right\rangle,
$$

where

$$
\begin{aligned}
& \left\langle\phi^{+}\right\rangle=U_{L}^{+}\left\langle C^{+}\right\rangle, \\
& \left\langle\phi^{-}\right\rangle=U_{L}^{-}\left\langle C^{-}\right\rangle,
\end{aligned}
$$

while $\left\langle\ldots{ }^{+}\right\rangle=\frac{1}{T} \int_{0}^{T_{C}}\left(\ldots{ }^{+}\right) d t$ and $\left\langle\ldots{ }^{-}\right\rangle=\frac{1}{T} \int_{T_{C}}^{T}\left(\ldots{ }^{-}\right) d t \quad$ are averaged values within the wave period $(T)$.

The complete sediment transport rate is a result of integration of the stream of $\left\langle\phi^{+/-}\right\rangle$over the depth $H$, as follows:

$$
\int_{0}^{H}\left\langle\phi^{+/-}\right\rangle d z=q_{x}^{+/-}
$$

which corresponds to the sediment transport rate $q_{x}^{+/-}$in the layer of the thickness $z_{m}^{+/-}$with the forward speed $U_{L_{1}}^{+/-}$in hydrodynamic equilibrium conditions, while:

$$
z_{m}=z_{m}^{+}+z_{m}^{-}
$$

and

$$
z_{m}^{+/-}=\frac{1}{\left(1-n_{p}\right)} \frac{q_{x}^{+/-} d t}{d x^{+/-}}
$$

The symbol $\left(\ldots{ }^{+-}\right)$combines two cases, i.e., the one described by $\left(\ldots{ }^{+}\right)$ for the wave crest and another one, by $\left.(. .)^{-}\right)$, for the wave trough.

Using the Eqs. 2, 4, and 5 in comparison with 17, 18, and 19, relation 21 may be transformed to the following expression describing the sediment transport rate:

$$
q_{x}^{+/-}=\left(1-n_{p}\right) z_{m}^{+/-} U_{L_{1}}^{+/-}=U_{L_{1}}^{+/-} \boldsymbol{\kappa}^{+/-} \int_{0}^{H}\left\langle C^{+/-}\right\rangle d z,
$$

where

$$
\kappa^{+/-}=\frac{U_{L}^{+/-}}{U_{L_{1}}^{+/-}} .
$$

Next, using relation 22, Eq. 10 takes the following form:

$$
\frac{\partial z_{m}}{\partial t}+\frac{1}{\left(1-n_{p}\right)}\left(\frac{\partial q_{x}^{+}}{\partial x^{+}}+\frac{\partial q_{x}^{-}}{\partial x^{-}}\right)=0 .
$$


Herein, the following should be taken into consideration:

$$
\frac{\partial q_{x}^{+}}{\partial x^{+}} \neq \frac{\partial q_{x}^{-}}{\partial x^{-}},
$$

when waves propagate over inclined bed. Indeed, the values of $q_{x}^{+}$and $q_{x}^{-}$ are interpreted as sediment transport rates under hydrodynamic equilibrium conditions during wave crest and trough duration, respectively. Both values are averaged within wave period $T$. These sediment transport rates (in accordance with Eq. 22) are in linear relations with thicknesses $z_{m}^{+/-}$. However, in view of Eq. 11, the relation between these sediment transport rates $q_{x}^{+}$and $q_{x}^{-}$and bed level of $z_{b}$ is still non-linear.

In order to solve Eq. 24, the first order "upwind" numerical scheme of FDM is proposed, in which for any assumed length $d x$ it is possible to calculate the time interval $d t$ according to Eq. 3:

$$
d t=\frac{\left(1-n_{p}\right) z_{\max } d x}{q_{\mathrm{rep}}^{+}+\left|q_{\mathrm{rep}}^{-}\right|},
$$

where the maximum value of $\left(q_{x}^{+}+\left|q_{x}^{-}\right|\right)$in a given calculation area and within a specified time interval is assumed as the representative $\left(q_{\text {rep }}^{+}+\left|q_{\text {rep }}^{-}\right|\right)$. Thus, it is necessary to determine the values of $q_{x}^{+}$and $q_{x}^{-}$in a given calculation area and within a specified time interval. It is postulated to use the three layer sediment transport model introduced by Kaczmarek et al. (2004) for hydrodynamic equilibrium conditions.

The model assumes that the movement of sediment is carried out in three layers (Fig. 1): bedload layer, contact load layer, and outer flow region, as a result of the shear stress impact on the bottom. In the area of each layer there is a different character of the deposit movement and the momentum exchange between the water and sediment particles. Hence they are described by various equations with boundary conditions permitting matching of velocities and concentrations in considered areas as to ensure the continuity of sediment movement description.

The model assumes that all fractions in the bedload layer move with the same speed in the form of water and solid mixture. It is assumed that the interactions between the sediment fractions are so strong that finer fractions are slowed down by the coarser ones, and finally all fractions move with the same speed. Thus, this layer does not apply to the simple summation of transport flow for individual fractions treated as the homogeneous sediment. 
The onshore sediment transport intensity in the bedload layer (for the duration of wave crest) $q_{b x}^{+}$and offshore $q_{b x}^{-}$(for the duration of wave trough) are defined as (see Sawczyński et al. 2011):

$$
q_{b x}^{+}=\frac{1}{T} \int_{0}^{T_{c}}\left(\int_{0}^{\delta_{b r}^{+}} u_{b r}^{+}\left(z^{\prime}, t\right) c_{b r}^{+}\left(z^{\prime}, t\right) d z^{\prime}\right) d t
$$

and

$$
q_{b x}^{-}=\frac{1}{T} \int_{T_{c}}^{T}\left(\int_{0}^{\delta_{b r}^{-}} u_{b r}^{-}\left(z^{\prime}, t\right) c_{b r}^{-}\left(z^{\prime}, t\right) d z^{\prime}\right) d t
$$

where $T_{c}$ is wave crest duration, $T$ is wave period, $\delta_{b r}^{+-}$represents bedload layer thickness, $u_{b r}^{+/-}$is instantaneous sediment velocity in bedload layer, $c_{b r}^{+/-}$is instantaneous sediment concentration in bedload layer, $z^{\prime}$ is elevation, while $z^{\prime}$ axis is directed vertically down.

The mathematical modelling takes into account the fact that the most intensive vertical sorting takes place in the process of raising grains in the contact load layer over the bottom. In the contact load layer, turbulent water pulsations and chaotic collisions between particles cause very strong transport differentiation of individual sediment fractions. Very close to the bottom, in a sublayer, bed slip speed is strongly revealed and there is a very strong interaction between the individual fractions. Further from the bottom, these interactions become weaker. However, at this level the concentration of the $i$-th fraction is still so high as to cause turbulence suppression which is assumed to be dependent on the grain diameter $d_{i}$. As a result of interactions described above, each $i$-th fraction moves with its own speed and is characterized by its own concentration. The interactions between fractions when coarser ones are accelerated by the finer ones result in the increase of speed of coarser fractions in the mixture. Further, coarser fraction concentrations are greater than the ones which would have been if the bottom had been homogenous and made of only one, corresponding fraction.

The onshore $q_{c x}^{+}$and the offshore $q_{c x}^{-}$sediment transport rates may be described as (see Sawczyński et al. 2011):

$$
q_{c x}^{+}=\sum_{i=1}^{N} n_{i}\left(\frac{1}{T} \int_{0}^{T_{c}}\left(\int_{0}^{\delta_{c r}} u_{c i}^{+}(z, t) c_{c i}^{+}(z, t) d z\right) d t\right)
$$

and

$$
q_{c x}^{-}=\sum_{i=1}^{N} n_{i}\left(\frac{1}{T} \int_{T_{c}}^{T}\left(\int_{0}^{\delta_{c r}} u_{c i}^{-}(z, t) c_{c i}^{-}(z, t) d z\right) d t\right)
$$


where $\delta_{c r}$ represents the contact load layer thickness, $n_{i}$ is the percentage content of the $i$-th fraction, $u_{c i}^{+/-}$is instantaneous velocity of the $i$-th fraction, and $c_{c i}^{+/-}$denotes instantaneous concentration of the $i$-th fraction in the contact load layer.

In the outer layer it is assumed that the particle size distribution of the transported sediment does not change along the distance from the bottom. The vertical distribution of concentration in this layer is described by a power function.

The sediment transport flow in the outer layer can be expressed by the following formulas (see Sawczyński et al. 2011):

$$
\begin{aligned}
& q_{o x}^{-}=\int_{\delta_{c r}}^{H} U_{o x}^{-}(z) C_{0}(z) d z, \\
& q_{o y}=\int_{\delta_{c r}}^{H} U_{o y}(z) C_{0}(z) d z,
\end{aligned}
$$

where $C_{0}$ means the value of suspended sediment concentration averaged in time, and $U_{o x}^{-}$and $U_{0 y}$ are velocities of the return current (directed towards the sea) and alongshore current, respectively.

\section{LABORATORY TESTS}

\subsection{Measurements of eroded thickness $\left(z_{m}\right)_{e}$. Experiment of "IBW PAN 2010"}

The wave flume in which the measurements of eroded thicknesses are conducted is $64.1 \mathrm{~m}$ long, $0.6 \mathrm{~m}$ wide, and $1.4 \mathrm{~m}$ high (Fig. 2). The vertical, mutually parallel channel walls are made of glass, which allows free observation of ongoing researches. The bottom of the channel is made of aluminium alloys.

Programmable and controlled by the computer and hydraulically driven piston-type flap generator provides the ability to produce waves with heights up to $0.6 \mathrm{~m}$ and any length of allocated time over $0.5 \mathrm{~s}$. Wave forcing element is a rigid vertical plate of the generator, subjected to horizontal oscillatory movements similarly to the movement of the piston inside the cylinder. The generator is located independently of the supporting structure of the flume, so that the transmission of undesired vibrations is reduced.

The final part of the flume is equipped with original wave energy absorber, made in the form of porous slope with 1:7 inclination and is composed of a dozen of plastic matt layers. That kind of structure allows to reduce the effects of reflected waves from the rear wall of the flume on wave propagation. 


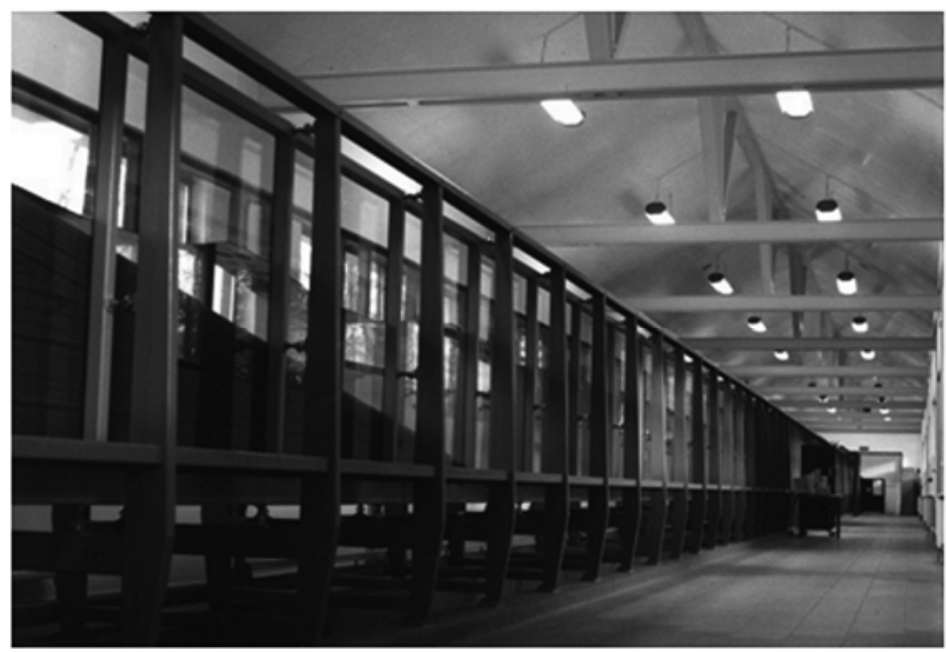

Fig. 2. Wave flume at IBW PAN in Gdańsk - "IBW PAN 2010" experiment (photo by Ł. Sobczak).

In order to measure the thickness of eroded sediment, the model of sand trap was used. This is made of waterproof plywood and plastic plates (Sawczyński 2012). Then, the model was placed on the bottom of the flume. The model of the sand trap consisted of two slopes, both inclined at 1:18, and the central box located between the slopes. The sand trap box was composed of three smaller parts: the central one of the dimensions of $20.0 \times 57.8 \times 10.0 \mathrm{~cm}$ and the two extreme parts, each one of dimensions of $57.8 \times 10.0 \times 10.0 \mathrm{~cm}$. The central box was filled with sand. Diagram of the experiment is presented in Fig. 3.

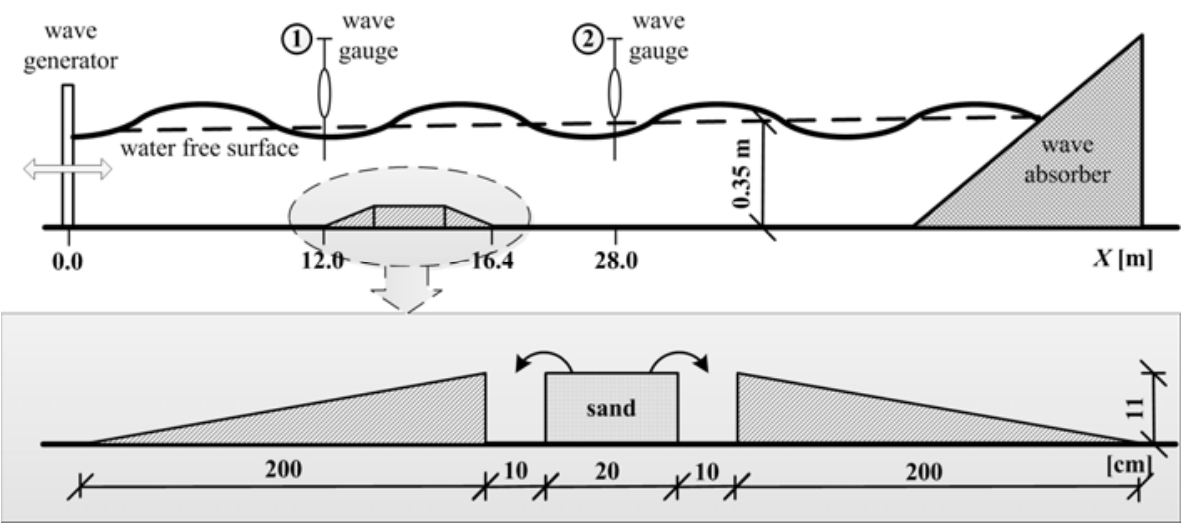

Fig. 3. Diagram of the "IBW PAN 2010" experiment. 
In order to determine the grain size of the sediment, the particle laser measure device of Analysette 22 MicroTec plus was used. The device measures with two lasers. The detector captures 108 measuring channels. The meter, by the usage of laser diffraction, allowed to analyze samples of a small amount of solid fractions in the range of diameters $0.01-2000 \mu \mathrm{m}$. Sediment used in experiments was sand originated from the beach of seaside town Lubiatowo, situated at south Baltic coast in Poland. For this purpose, the particle size laser measuring device was used. Particle size analyses were performed using the "wet method" for the two randomly taken sand samples. Each of them was analyzed twice and identical results were obtained. On the basis of those analysis, the following representative sand parameters were acquired - the diameter $d_{50}=0.27 \mathrm{~mm}$ and $d_{90}=0.42 \mathrm{~mm}$.

Two resistance wave probes were used for measurements of water free surface elevations. A resistive element of these probes is water layer between two vertical non-insulated electrodes. The wave height measurement is based on a variation of electrical resistance of water between two electrodes. The device accuracy is $\pm 1 \mathrm{~mm}$.

For measurements of the flow velocity it was necessary to use the ultrasonic Acoustic Doppler Velocimeter (ADV) which enabled simultaneous measurements of the three velocity components in a configurable range of $\pm 0.01,0.1,0.3,2.0,4.0$, and $7.0 \mathrm{~m} / \mathrm{s}$ with an accuracy of $\pm 0.5 \%$ of measured value $\pm 1 \mathrm{~mm} / \mathrm{s}$. The sampling rate of the device is $1-64 \mathrm{~Hz}$, while the sound frequency is $6 \mathrm{MHz}$.

Within the frame of the experiment, the two measuring tests (T4 and T5) were carried out for the same sand and different wave conditions (Sawczyński 2012). The change in wave conditions concerned only the wave height, while the wave period remained unchanged. The computer software controlled wave generation process and regular and sine waves were to produce. Wave parameters were recorded by the two wave probes placed along the flume, downstream and upstream the sand trap model (Fig. 3). In Table 1 there are shown basic parameters of the experiment. The wave height of each T4 and T5 test marked by symbol $H_{w}$ determines the time averaged value taken from two wave probes.

Measurements of wave height and period took place using two wave probes arranged along the flume, as shown in Fig. 3. Because of the fact that the wave parameters were kept constant during undulation, the recording of wave parameters had been made fragmentarily at selected time intervals.

Wave height records with duration of twenty seconds of T4 and T5 tests are shown in Fig. 4 as an example while time averaged values of the wave height are shown in Table 2.

It can be seen from Fig. 4 that regular sine waves were subjected to transformation process due to their propagation along the flume. The records 
Table 1

Basic data of "IBW PAN 2010" experiment

\begin{tabular}{|l|c|c|c|}
\hline \multicolumn{1}{|c|}{ Parameter } & Symbol & Value & Unit \\
\hline Water depth & $h_{0}$ & 0.35 & {$[\mathrm{~m}]$} \\
Wave height T4/T5 & $H_{w}$ & $6.77 / 4.95$ & {$[\mathrm{~cm}]$} \\
Undulation duration time T4/T5 & $T_{w}$ & $25 / 60$ & {$[\mathrm{~min}]$} \\
Wave peak period T4/T5 & $T_{p}$ & $2.0 / 2.0$ & {$[\mathrm{~s}]$} \\
Water temperature & $T$ & 18.0 & {$\left[{ }^{\circ} \mathrm{C}\right]$} \\
Representative diameter of sand grains & $d_{50} ; d_{90}$ & $0.27 ; 0.42$ & {$[\mathrm{~mm}]$} \\
Sand density & $\rho_{s}$ & 2650 & {$\left[\mathrm{~kg} / \mathrm{m}^{3}\right]$} \\
Fluid density & $\rho_{w}$ & 1000 & {$\left[\mathrm{~kg} / \mathrm{m}^{3}\right]$} \\
Sand porosity & $n_{p}$ & 0.4 & {$[-]$} \\
\hline
\end{tabular}

Table 2

Time averaged wave heights of tests T4 and T5 - "IBW PAN 2010" experiment

\begin{tabular}{|c|c|c|c|}
\hline \multirow{2}{*}{ Test no. } & \multicolumn{3}{|c|}{ Wave height $H_{w}[\mathrm{~cm}]$} \\
\cline { 2 - 4 } & Probe no. 1 & Probe no. 2 & Average \\
\hline T4 & 7.65 & 5.90 & 6.77 \\
T5 & 5.70 & 4.20 & 4.95 \\
\hline
\end{tabular}

of wave parameters taken from the probe 1 installed upstream the model (Fig. 3) for both tests, T4 and T5, show that amplitudes of wave crest are bigger than of the trough. However, the difference in these amplitudes is much bigger in T4 test when higher waves were generated. In addition to the amplitude difference, it is also possible to observe shape differentiation between wave crests and troughs. In both tests, the elevations during wave crests were higher and steeper than during troughs. Simultaneously, the duration of wave crests was shorter than that of troughs. Moreover, this description of waves is identical with the one of the second Stokes' wave approach theory.

The sand originally located in the central box of the sand trap was transported to the two extreme parts as a result of undulation of the free water surface (Fig. 3). The measurement diagram is shown in Fig. 6. During wave crest, sand was transported towards the right trap and during wave trough towards the left part. In order to determine the volume of sand accumulated in extreme traps, each time after completion of the undulation, the mixture of sand and water was pumped from the two extreme traps. The siphoning method was used with the silicone hoses. The samples were then dried and 
(a)

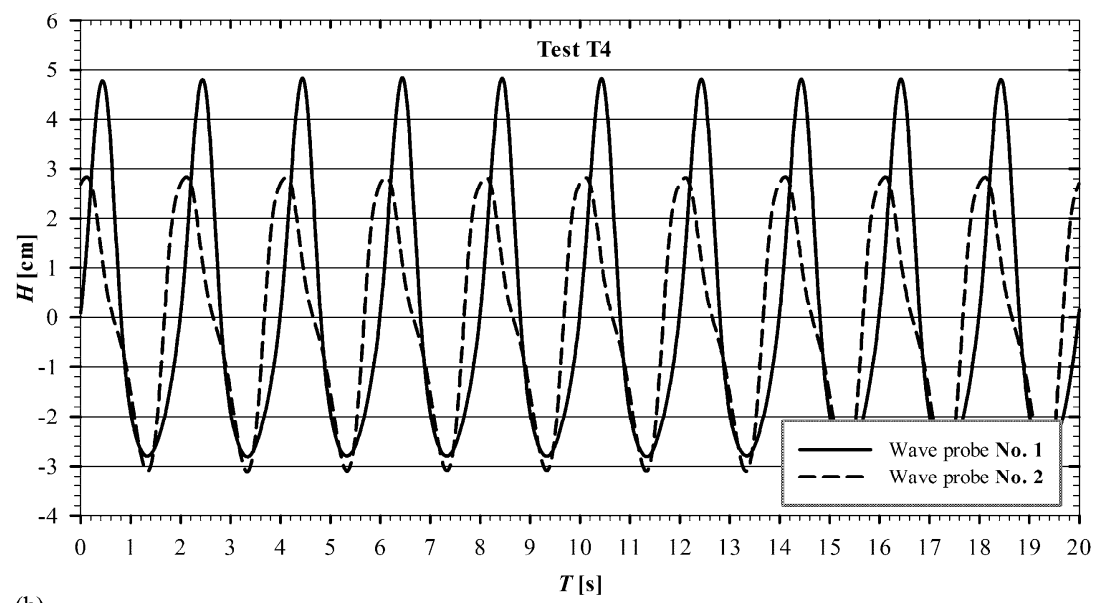

(b)

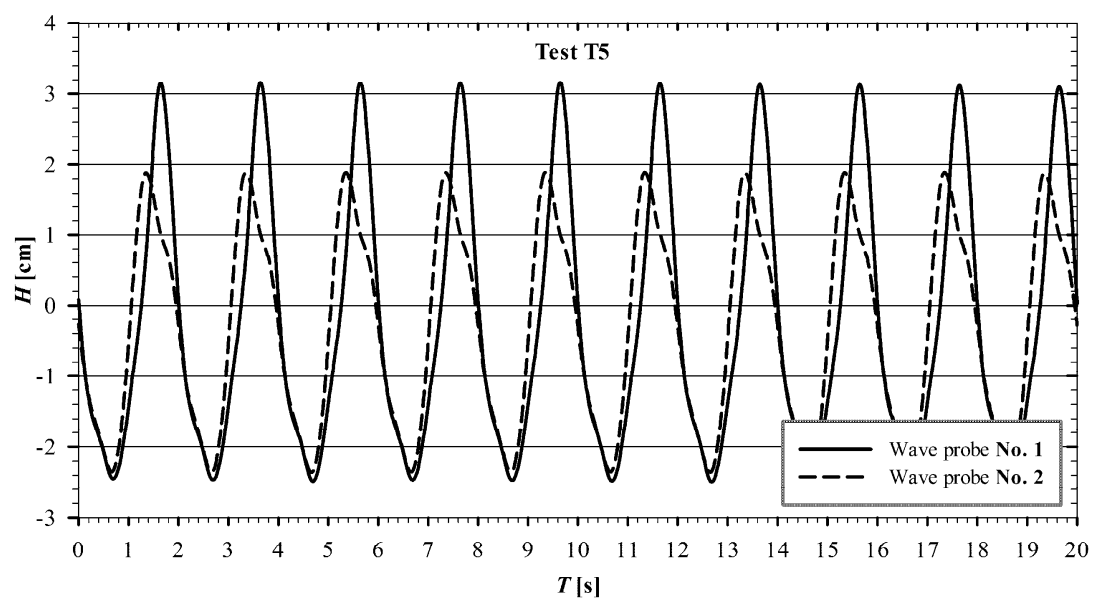

Fig. 4. "IBW PAN 2010" experiment: record of wave elevations (wave probe no. 1 solid line, wave probe no. 2 - dashed line): (a) test T4, and (b) test T5.

the sand volume taken from each trap was determined. On this basis, the thickness of the layer eroded from the central box was calculated. The results are shown in Table 3.

It is worth emphasizing that the duration of T4 test was three times smaller than T5 test's. Recorded wave height during the test T4 was greater than the one of test T5 and it was a reason why the total amount of eroded sediment in T4 test was almost twice bigger than in T5 test. Further, it is clear that for both measurement tests, a greater amount of sediment taken from the central box was deposited in the right trap (Table 3). This means 
(a)

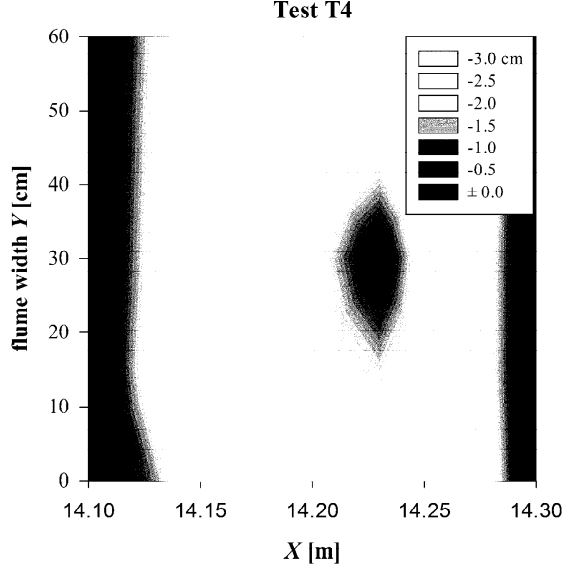

(b)

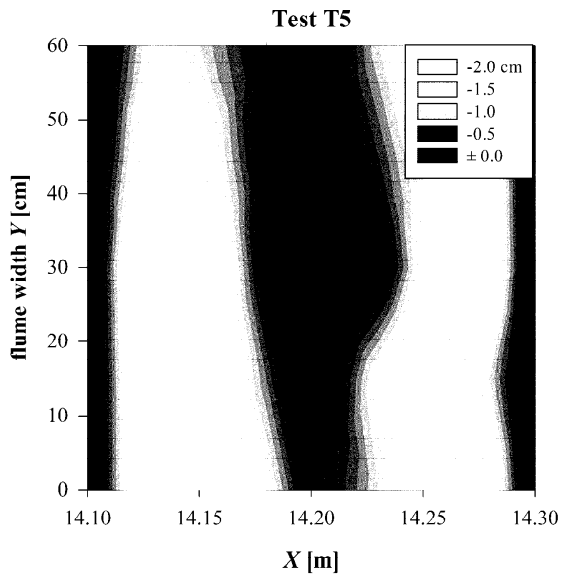

Fig. 5. Final bathymetry of "IBW PAN 2010" experiment: (a) test T4, and (b) test T5.

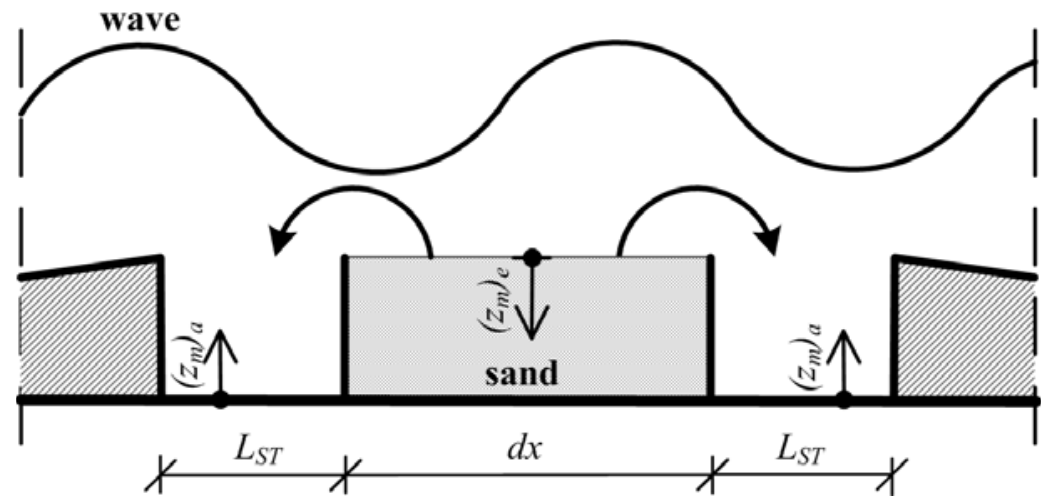

Fig. 6. Diagram of eroded thickness measurements $\left(z_{m}\right)_{e}-$ "IBW PAN 2010" experiment.

Table 3

Measured amount of eroded sand - "IBW PAN 2010" experiment

\begin{tabular}{|c|c|c|c|c|c|}
\hline $\begin{array}{c}\text { Test } \\
\text { no. }\end{array}$ & $\begin{array}{c}\text { Undulation } \\
\text { time } \\
{[\mathrm{min}]}\end{array}$ & $\begin{array}{c}\text { Amount of } \\
\text { sediment in } \\
\text { the left box } \\
{\left[\mathrm{cm}^{3}\right]}\end{array}$ & $\begin{array}{c}\text { Amount of } \\
\text { sediment in } \\
\text { the right box } \\
{\left[\mathrm{cm}^{3}\right]}\end{array}$ & $\begin{array}{c}\text { Total amount of } \\
\text { the sediment } \\
{\left[\mathrm{cm}^{3}\right]}\end{array}$ & $\begin{array}{c}\text { Erosion } \\
\text { thickness } \\
\left(z_{m}\right)_{e} \\
{[\mathrm{~cm}]}\end{array}$ \\
\hline T4 & 25 & 780 & 1150 & 1930 & 1.67 \\
T5 & 60 & 460 & 580 & 1040 & 0.90 \\
\hline
\end{tabular}


that the greater amount of sediment was transported during the phase of wave crest than during wave trough. Of course, it is a consequence of wave asymmetry.

After completion of the undulation, the bathymetry was carried out manually in the central box. The measurements were taken point by point every $2.0 \div 2.5 \mathrm{~cm}$ in the longitudinal direction and approximately every $10 \mathrm{~cm}$ in the transversal direction. Total number of measurements per test was 35. Intermediate data was obtained using linear interpolation technique. The results of final bathymetry of T4 and T5 tests are presented in Fig. 5. It is noticeable that, for both measurement tests, erosion on the left side of the central box was bigger than on the right side. This reflects the dominance of sand transport during wave crest, resulting from the asymmetry of propagating waves (see Fig. 4). Moreover, it documents the dominant impact of wave crest on the process of bathymetric changes.

\subsection{Measurements of accumulated thickness $\left(z_{m}\right)_{a}$ Experiment of "IBW PAN 1996"}

The experiment was conducted at the Institute of Hydroengineering, Polish Academy of Sciences in Gdańsk in 1996 (Kaczmarek 1999) in the wave flume $0.5 \mathrm{~m}$ wide, $25.5 \mathrm{~m}$ long, and maximal possible filling of up to $0.7 \mathrm{~m}$. In the wave flume, in conditions of constant filling of $h=0.5 \mathrm{~m}$, the regular (tests $1,2,3,4,11,12$ ) and irregular (tests $5,6,7,8,9,10$ ) undulations were generated. The experiment was repeated several times for each set of hydrodynamic parameters. A total number of 141 measurements were made for 12 tests. Figure 7 presents the diagram of the experiment.

At the beginning and at the end of the flume, its bottom was covered by concrete slabs with a thickness of $0.080 \mathrm{~m}$. The central part of the flume was filled with sand with representative diameters $d_{50}=0.22 \mathrm{~mm}$ and $d_{90}=$ $0.42 \mathrm{~mm}$. The sand thickness was equal to the thickness of the concrete slab. The length of the section filled with sand was $7.0 \mathrm{~m}$. At a distance of $2.0 \mathrm{~m}$ from the end of the section of concrete slab, the sand trap was situated. It

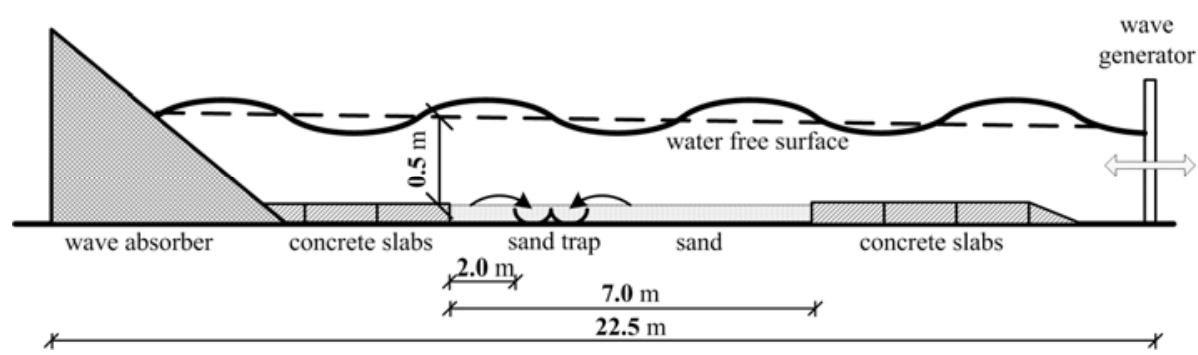

Fig. 7. Diagram of the "IBW PAN 1996" experiment. 
was used to collect trapped sand and hence it was possible to measure accumulated thickness of the sediment.

The main objective of the measurements - at the contemporary stage of research - was to determine the amount of sediment transported mainly in the bedload layer, in the direction of outflow and inflow by measuring the amount of sediment which flows into the sand trap. The sand trap consisted of two separate chambers with a height of $0.063 \mathrm{~m}$. During the experiment, the wave conditions were generated within a range for which Shields parameter $\Theta_{2.5}$ determined for the representative diameter $d_{50}=0.22 \mathrm{~mm}$, contained within the range $0.085 \leq \Theta_{2.5} \leq 0.4$, which corresponded to the regime of rippled bed. Thus, measurements were made after the time required for the full development of bed forms, i.e., after 25-60 minute duration of continuous undulation. By this time, the sand trap was covered with a lid. Then, the cover was removed and undulation was continued for 1.2 to 15 minutes. In this time, the trap was filled with sand. In the next stage of the experiment, the sand was sucked from the sand trap outside the flume and then it was weighed. Finally, by determining the volume of sand pumped from inside the sand trap, accumulated thickness was determined.

\section{COMPARISON BETWEEN RESULTS OF NUMERICAL AND PHYSICAL MODEL}

\subsection{Input data for calculations}

The percentage contents of different sediment fractions for both experiments are shown in Table 4. This data was used as an input one in the calculations of sediment transport rates $q_{x}^{+}$and $q_{x}^{-}$using Eqs. 27-32. The input data maintains measured indicators of $\mathrm{d}_{50}$ and $\mathrm{d}_{90}$.

The wave parameters (wave heights $H$ and periods $T$ ), taken from Kaczmarek (1999), were used as an input data in calculations conducted for an experiment of "IBW PAN 1996". For all 12 measurement tests, the sine waves theory was used in modelling.

In case of the "IBW PAN 2010" experiment, the first wave probe was installed just in front of the sand trap, at a distance of $12 \mathrm{~m}$ from the wave generator. The second wave probe was situated $28 \mathrm{~m}$ from the wave generator (Fig. 3). In view of the fact that the first wave probe was situated just in front of the sand trap, it was reasonable to treat its wave record as an input data for sediment transport model. The data concerns both the wave height and the shape of the wave run. Basing on the wave first probe record, it was decided to use the second Stokes' approximation in order to reproduce shape of the wave run. The proposed wave approximation was confirmed by the second wave probe, although further wave deformation had been observed due to its propagation along the flume, including the distance over the sand trap. 
Table 4

Percentage contents of sediment fractions used in calculations performed for experiments of "IBW PAN 1996" and "IBW PAN 2010"

\begin{tabular}{|c|c|c|c|}
\hline \multicolumn{2}{|c|}{ IBW PAN 1996} & \multicolumn{2}{c|}{ IBW PAN 2010 } \\
\hline $\begin{array}{c}d_{50}=0.22 \mathrm{~mm} ; d_{90}=0.42 \mathrm{~mm} \\
\begin{array}{c}\text { Fraction diameter } \\
{[\mathrm{mm}]}\end{array}\end{array}$ & $\begin{array}{c}\text { Percentage fraction } \\
\text { content }[\%]\end{array}$ & $\begin{array}{c}\text { Fraction diameter } \\
{[\mathrm{mm}]}\end{array}$ & $\begin{array}{c}\text { Percentage fraction } \\
\text { content }[\%]\end{array}$ \\
\hline 0.10 & 7 & 0.08 & 32 \\
0.18 & 23 & 0.25 & 10 \\
0.20 & 20 & 0.28 & 10 \\
0.22 & 8 & 0.31 & 21 \\
0.26 & 8 & 0.37 & 9 \\
0.28 & 13 & 0.41 & 7 \\
0.30 & 8 & 0.45 & 5 \\
0.32 & 6 & 0.50 & 6 \\
0.34 & 4 & & \\
0.36 & 3 & & \\
\hline
\end{tabular}

\subsection{Calculation results in comparison to measurements}

Consideration regarding sediment transport under hydrodynamic equilibrium conditions involves the discussion of Eq. 22 linearity. This linearity seems to be confirmed by the results from "IBW PAN 1996" and "IBW PAN 2010" experiments.

Using the Eq. 22, with respect to the above-mentioned experiments, it is possible to write as follows:

$$
\frac{\left(q_{x}^{+}+\left|q_{x}^{-}\right|\right)}{L_{S T}}=\frac{\mathrm{Vol}}{B_{S T} L_{S T} d t}=\frac{\left(1-n_{p}\right)\left(z_{m}^{+}+z_{m}^{-}\right)}{d t},
$$

where $B_{S T}$ and $L_{S T}$ are the sand trap width [m] and length [m], respectively, $\mathrm{Vol} / d t$ denotes the volume of sediment motion in time $[\mathrm{m} / \mathrm{s}]$; it is assumed that $d x=L_{S T}$.

In order to compare the calculation results of the bed layer thicknesses $\left(z_{m}^{+}+z_{m}^{-}\right)_{\text {cal }}$, where sediment is in apparent rectilinear motion, with the measurement results $\left(z_{m}^{+}+z_{m}^{-}\right)_{\text {meas }}$, it is convenient to present Eq. 33 in the following form:

$$
\left(1-n_{p}\right) \frac{\left(z_{m}^{+}+z_{m}^{-}\right)_{\mathrm{cal}}}{d t}=\frac{\left(q_{x}^{+}+\left|q_{x}^{-}\right|\right)_{\mathrm{cal}}}{L_{S T}}
$$


while

$$
\left(1-n_{p}\right) \frac{\left(z_{m}^{+}+z_{m}^{-}\right)_{\text {meas }}}{\Delta t_{\text {meas }}}=\frac{\left(q_{x}^{+}+\left|q_{x}^{-}\right|\right)_{\text {meas }}}{L_{S T}}=\frac{\mathrm{Vol}_{\text {meas }}}{B_{S T} L_{S T} \Delta t_{\text {meas }}},
$$

where $\left(q_{x}^{+}+\left|q_{x}^{-}\right|\right)_{\text {meas }}$ denotes the measurement sediment transport rate determined on the basis of $\mathrm{Vol}_{\text {meas }}$ (see Eq. 35), $\left(q_{x}^{+}+\left|q_{x}^{-}\right|\right)_{\text {cal }}$ is the sediment transport rate calculated using Eqs. 27-32, $\mathrm{Vol}_{\text {meas }}$ is the measured volume of the sediment stopped in (or eroded from) the sand trap in time $\Delta t_{\text {meas }}$.

The results of the comparison are presented in Fig. 8. The dashed lines shown in Fig. 8 are inclined in relations 1:0.75, 1:1, and 1:1.5. The presented cloud of points is arranged in a very narrow area, in the close vicinity of the straight line inclined at the angle of $45^{\circ}$. This convergence of results indicates a very good compatibility between results of calculations and results obtained from the measurements.

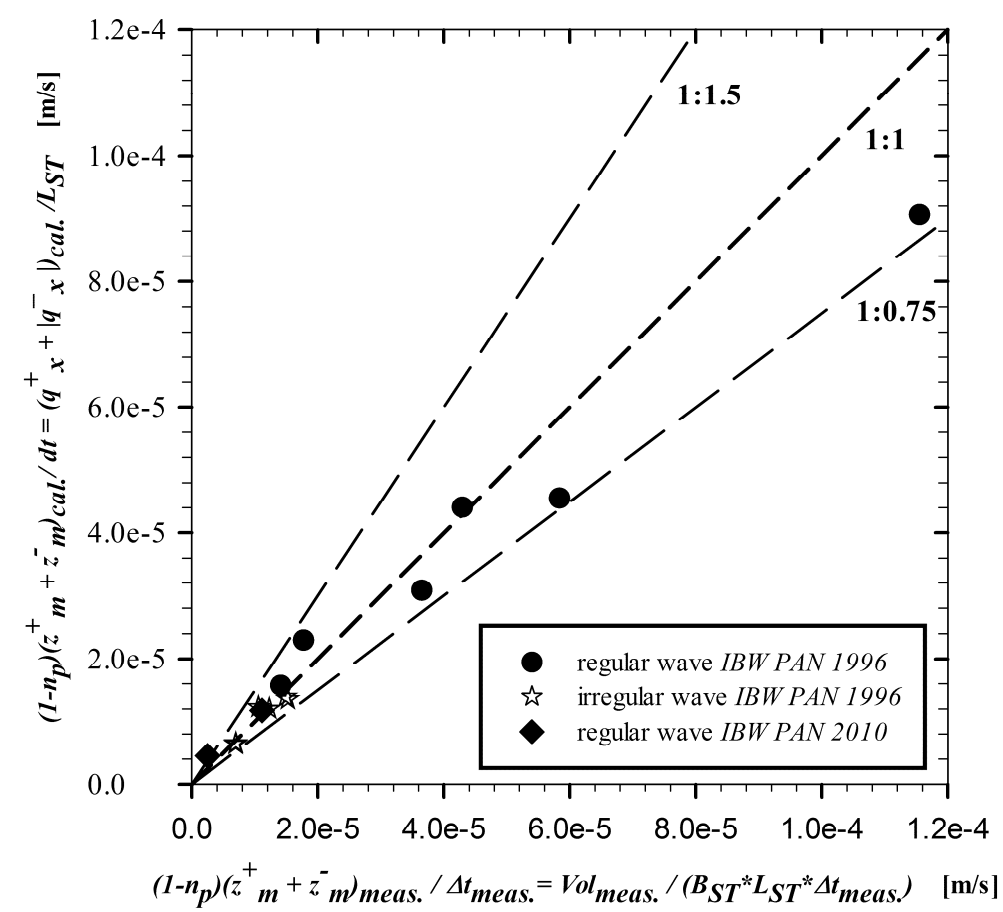

Fig. 8. Comparison between calculations and measurements of $\left(z_{m}^{+}+z_{m}^{-}\right)$; black symbols for regular waves: circles - experiment of "IBW PAN 1996", diamonds experiment of "IBW PAN 2010"; white star symbols for irregular waves - experiment of "IBW PAN 1996"; inclination of dashed lines: 1:0.75, 1:1, and 1:1.5. 
The analysis of linearity of the relationship between the results of calculated sediment transport rates $\left(q_{x}^{+}+\left|q_{x}^{-}\right|\right)_{\text {cal }}$ and the results of measurements $\left(1-n_{p}\right) \frac{\left(z_{m}^{+}+z_{m}^{-}\right)_{\text {meas }}}{\Delta t_{\text {meas }}}$ are presented in Fig. 9. Experimental values were presented as averaged values from the results obtained during measurements. The relation between calculated values of sediment transport rate $\left(q_{x}^{+}+\left|q_{x}^{-}\right|\right)_{\text {cal }}$ and measured values $\left(1-n_{p}\right) \frac{\left(z_{m}^{+}+z_{m}^{-}\right)_{\text {meas }}}{\Delta t_{\text {meas }}}$ of the eroded ("IBW PAN 2010") or accumulated ("IBW PAN 1996") thicknesses, clearly expresses its linear character. The intersection of a straight line with the elevation axis (Fig. 9) seems to indicate the linear relationship validity only for such sediment transport rate that allows to establish the minimal thickness of $\left(z_{m 0}^{+}+z_{m 0}^{-}\right)$in time of $d t=\Delta t_{\text {meas }}$ in the sand trap of the length $d x=L_{S T}$. In other words, the sediment transport rate smaller than the one resulting from

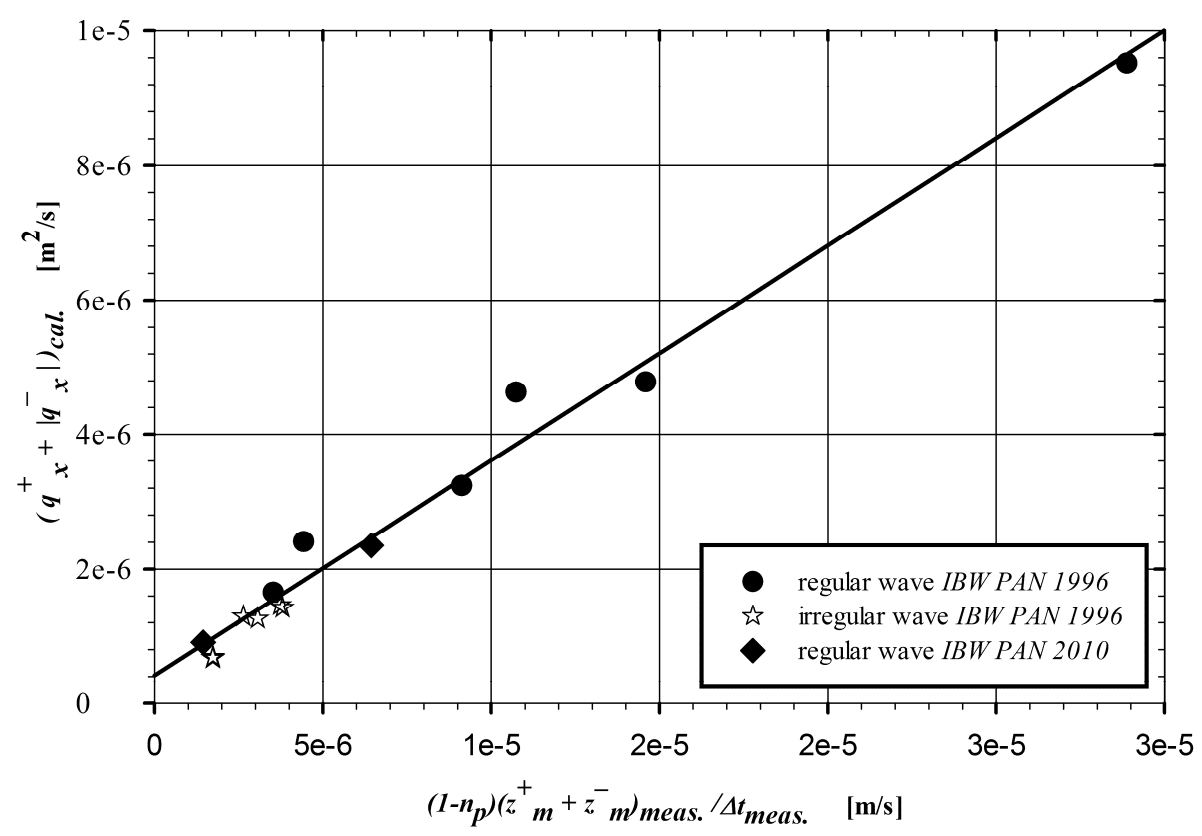

Fig. 9. The analysis of linearity of the relationship between results of sediment transport rate calculations and the results of measurements of eroded/accumulated thicknesses; black symbols for regular waves: circles - experiment of "IBW PAN 1996", diamonds - experiment of "IBW PAN 2010"; white star symbols for irregular waves - experiment of "IBW PAN 1996"; best fit - solid line. 
the intersection of the best fit with the elevation axis does not fill the trap with sediment of minimal thickness along the entire length and in time $\Delta t_{\text {meas }}$.

Equation 33 may be rewritten in the following form:

$$
\left(q_{x}^{+}+\left|q_{x}^{-}\right|\right) d t=\left(1-n_{p}\right)\left(z_{m}^{+}+z_{m}^{-}\right) L_{S T} .
$$

Using Eqs. 22 and 23, it is possible to transform Eq. 36 into the following form:

$$
\begin{aligned}
\left(q_{x}^{+}+\left|q_{x}^{-}\right|\right) d t & =\left(1-n_{p}\right)\left(\kappa^{+} \int_{z_{m}^{+}}^{H}\left\langle C^{+}\right\rangle d z+\kappa^{-} \int_{z_{m}^{-}}^{H}\left\langle C^{-}\right\rangle d z\right) L_{S T} \\
& =\left(1-n_{p}\right)\left[\left(\kappa^{+}-1\right)+1\right] z_{m 0}^{+} L_{S T}+\left(1-n_{p}\right)\left[\left(\kappa^{-}-1\right)+1\right] z_{m 0}^{-} L_{S T} \\
& =\left(1-n_{p}\right)\left(\kappa^{+}-1\right) z_{m 0}^{+} L_{S T}+\left(1-n_{p}\right)\left(\kappa^{-}-1\right) z_{m 0}^{-} L_{S T}+\left(1-n_{p}\right)\left(z_{m 0}^{+}+z_{m 0}^{-}\right) L_{S T}
\end{aligned}
$$

from which

$$
\left(q_{x}^{+}+\left|q_{x}^{-}\right|\right)=\left(1-n_{p}\right)\left(\kappa^{+}-1\right) z_{m 0}^{+} \frac{L_{S T}}{d t}+\left(1-n_{p}\right)\left(\kappa^{-}-1\right) z_{m 0}^{-} \frac{L_{S T}}{d t}+\left(q_{x 0}^{+}+\left|q_{x 0}^{-}\right|\right),
$$

where

$$
\left(q_{x 0}^{+}+\left|q_{x 0}^{-}\right|\right)=\left(1-n_{p}\right)+\left(z_{m 0}^{+}+z_{m 0}^{-}\right) \frac{L_{S T}}{d t} .
$$

To clarify, it is more convenient to present Eq. 38 in a slightly different form:

$$
\left(q_{x}^{+}+\left|q_{x}^{-}\right|\right)_{\text {cal }}-\left(q_{x 0}^{+}+\left|q_{x 0}^{-}\right|\right)=\left(1-n_{p}\right) \frac{L_{S T}}{\Delta t_{\text {meas }}}\left(z_{m}^{+}+z_{m}^{-}\right)_{\text {meas }} .
$$

\section{BED RESPONSE: DISCUSSION OF THE RESULTS}

During the experiments (tests T4 and T5) concerning collecting data of eroded thickness $\left(z_{m}^{+}+z_{m}^{-}\right)_{\text {meas }}$, the measurements of depths in the central box of trap (Fig. 6) were carried out each time after completion of wave generation process in the wave flume. Hence, the bathymetry map was completed.

The averaged bathymetry results in the longitudinal section of the central box of the trap, for T4 and T5 tests, are presented in Fig. 10. The eroded thicknesses $\left(z_{m}^{+}+z_{m}^{-}\right)^{T 4}$ and $\left(z_{m}^{+}+z_{m}^{-}\right)^{T 5}$ corresponding to them were estimated in a way that the erosion areas, determined by the bathymetry T4 and T5, are equal to rectangle ones, $\left(z_{m}^{+}+z_{m}^{-}\right)^{T 4} L_{S T}$ and $\left(z_{m}^{+}+z_{m}^{-}\right)^{T 5} L_{S T}$, respectively. 


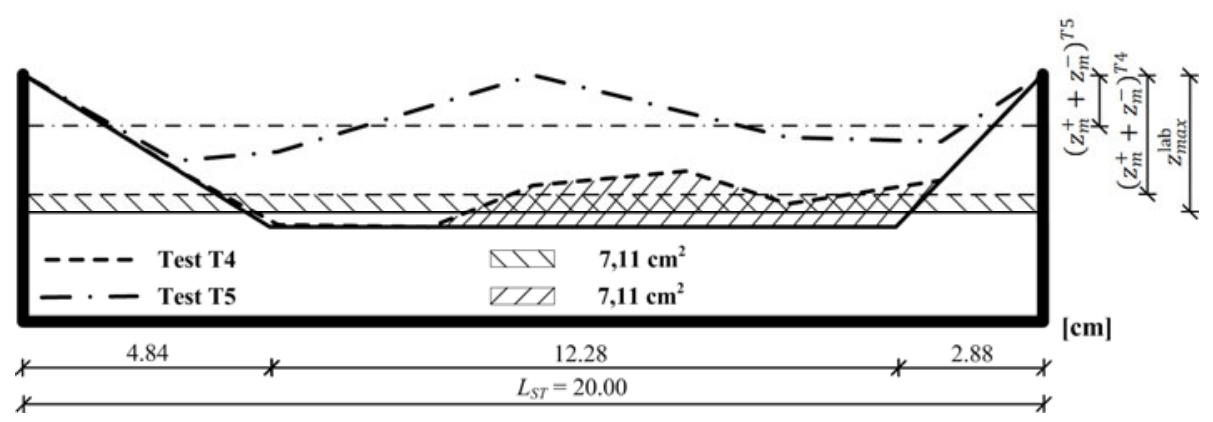

Fig. 10. Bathymetry results in the longitudinal section of the trap for T4 and T5 tests; trapezoid envelope (solid line), T4 bathymetry (dashed line), and T5 bathymetry (dash-dot line).

Additionally, Fig. 10 shows the value of $z_{\max }^{\text {lab }}$, which was estimated from the experiments. This value was established whilst the rectangle area, expressed by the relation of $L_{S T} z_{\max }^{\mathrm{lab}}$, is equal to the trapezoid area with inclined sides, as shown in Fig. 10 and a height for which the area expressed by the relation of $L_{S T}\left[z_{\max }^{\mathrm{lab}}-\left(z_{m}^{+}+z_{m}^{-}\right)^{T 4}\right]$ is approximately equal to the one between the trapezoid envelope and bathymetry of T4. Therefore, it is postulated that while the thickness $\left(z_{m}^{+}+z_{m}^{-}\right)^{T 4}$ reaches the value of $z_{\max }^{\text {lab }}$, the ultimate bathymetry coincides with the trapezoid envelope. It is worth noticing that the value $z_{\max }^{\text {lab }}=2.72 \mathrm{~cm}$ is close to $z_{\max }^{\text {field }}=2.75 \mathrm{~cm}$, assessed in the experiments conducted on the Atlantic updrift coast with the use of fluorescent tracers (Balouin et al. 2005) and close to $z_{\max }^{\text {field }}=2-3 \mathrm{~cm}$ assessed in the former experiments carried out in the Baltic coastal zone by Pruszak et al. (1996).

The trapezoid envelope can be also deduced from Eq. 3. This relation shows that the amount of erosion of the bed, specified by the relationship of $q_{x} d t$, is equal to the triangle area with the side of $d x$ and height of $2 z_{m}$. This triangle area is equal to the rectangle one with constant thickness erosion $z_{m}$ over the entire length $d x$. The situation described above occurs when $d x \leq(d x)_{\text {lim. }}$. Boundary length $(d x)_{\text {lim }}$ does not depend on the transport rate and it is related to the size of $z_{\max }$ in the following way:

$$
(d x)_{\lim }=\frac{4 z_{\max }}{\operatorname{tg} \varphi},
$$

where $\operatorname{tg} \varphi$ is the underwater slope, which must be determined from an experiment. The experiments presented above enable to assess the incline angle of the underwater slope as $38^{\circ}$. 
When $d x \geq(d x)_{\text {lim }}$ and when $z_{m}=z_{\max }$, it is expected that the erosion area of the bed takes the form of a trapezoid, whose area is equal to the calculated one with a constant thickness erosion $z_{m}=z_{\max }$, along the entire length $d x$. When $z_{m}<z_{\max }$, the erosion area boils down to this part of the trapezoid, which is the difference between its area and a part of it where the sediments still remain. Of course, the erosion area is equal to the rectangle one with the dimensions of $d x$ and $z_{m}$.

\section{CONCLUSIONS}

The paper presents the results of laboratory measurements of the thickness of eroded bottom sediment ("IBW PAN 2010"). Within the frame of the experiment, the two tests concerning the measurement of eroded thickness have been carried out for the sand collected from the south Baltic coast in Poland. The sand originally placed in the sand trap was eroded to the outside of the trap under the influence of the oscillating movement of water. After completion of the undulations, the bathymetry data was completed in the sand trap. After that, it was possible to determine the thickness $z_{m}$ of the sand trap layer from which sediments had been eroded.

The laboratory experiments were carried out under hydrodynamic equilibrium conditions, when the stream of sediments picked up from the bed with length $d x$, averaged in time $d t$, equals (at each level) the stream of sediments falling onto the bed. Because the bottom outside the sand trap was made of concrete, it is not difficult to imagine that all the sediments moving as sediment transport under hydrodynamic equilibrium conditions originates from that bed structure.

The measurements of a bed layer thickness where the densely packed grains participate in the apparent rectilinear and translational motion were compared with calculations and a good accuracy was achieved. Further, the results of thickness measurements are used to confirm the hypothesis of linear relation between sediment transport rate and the thickness $z_{m}$ of a bed layer, participating in the apparent motion. Under the hydrodynamic equilibrium conditions, the apparent bed motion is caused by the actual flow of sediments over the bed in the form of jumps in saltation motion.

The linear form of the relationship between sediment transport rates and the thickness $z_{m}$ of the layer in apparent flow was also documented by the results of experiments conducted in the laboratory IBW PAN in 1996. It is worth noticing, however, that the transport rate still remains a nonlinear function of the elevation of the bed level.

This linear relationship allows to use the first order "upwind" numerical scheme of FDM in the bathymetry changes calculations and, thus, it provides an accurate solution. However, in order to solve the equation, describing the changes in bathymetry in time and space, properly it is necessary to carry out 
the decomposition of the sediment transport into the transport in the positive direction - onshore and negative direction - offshore. Onshore sediment transport takes place during the wave crest and offshore transport during the wave trough duration.

As a result of bed response to sediment transport, a bed erosion area is created. It is assumed that bed erosion (determined by the thickness $z_{m}$ ) is constant at the entire length of this area.

The laboratory experiments indicate, however, that when the thickness $z_{m}$ reaches the value of $z_{\max }$, the bathymetry of the erosion area coincides with the trapezoid envelope, whose area is equal to the one of the rectangle with the thickness of $z_{\max }$.

When $z_{m}<z_{\max }$ the area of erosion reduces to this part of the trapezoid which is the difference between its area and that part of it where the sediments still remain. The value of $z_{\max }$ assessed in the laboratory experiments is close to values obtained in the field experiments conducted on the Atlantic and the Baltic coasts.

Acknowledgements. Laboratory measurements for which the results are presented in this paper were carried out within the framework of the Regional Operational Programme for Pomorskie Voivodeship for the years 2007-2013, under the title of "Construction of the network of knowledge transfer concerning directions and possibilities of the development of researches in the wave laboratory in situ with the usage of the innovative research equipment". The work is based on the Ph.D. Thesis (Sawczyński 2012). Authors would like to express their thanks for Reviewers' effort and criticism essential to make the paper more transparent and consistent.

\section{References}

Balouin, Y., H. Howa, R. Pedreros, and D. Michel (2005), Longshore sediment movements from tracers and models, Praia de Faro, South Portugal, J. Coast. Res. 21, 1, 146-156, DOI: 10.2112/01066.1.

Bialik, R.J. (2013), Numerical study of near-bed turbulence structures influence on the initiation of saltating grains movement, J. Hydrol. Hydromech. 61, 3, 202-207, DOI: 10.2478/johh-2013-0026.

Bialik, R.J., and W. Czernuszenko (2013), On the numerical analysis of bed-load transport of saltating grains, Int. J. Sediment Res. 28, 3, 413-420, DOI: $10.1016 / \mathrm{S} 1001-6279(13) 60051-7$. 
Bialik, R.J., V.I. Nikora, and P.M. Rowiński (2012), 3D Lagrangian modelling of saltating particles diffusion in turbulent water flow, Acta Geophys. 60, 6, 1639-1660, DOI: 10.2478/s11600-012-0003-2.

Callaghan, D.P., F. Saint-Cast, P. Nielsen, and T.E. Baldock (2006), Numerical solutions of the sediment conservation law; a review and improved formulation for coastal morphological modelling, Coast. Eng. 53, 7, 557-571, DOI: 10.1016/j.coastaleng.2006.03.001.

Cayocca, F. (2001), Long-term morphological modeling of a tidal inlet: the Arcachon Basin, France, Coast. Eng. 42, 2, 115-142, DOI: 10.1016/s03783839(00)00053-3.

Chiang, Y.-Ch., and S.-S. Hsiao (2011), Coastal morphological modeling. In: A.J. Manning (ed.), Sediment Transport in Aquatic Environments, InTech, Shanghai, 203-230, DOI: 10.5772/22076.

Chiang, Y.-Ch., S.-S. Hsiao, and M.-C. Lin (2010), Numerical solutions of coastal morphodynamic evolution for complex topography, J. Marine Sci. Tech. 18, 3, 333-344.

Einstein, H.A. (1950), The Bed-load Function for Sediment Transportation in Open Channel Flows, Technical Bulletin, No. 1026, United States Department of Agriculture, Washington D.C., 71 pp.

Johnson, H.K., and J.A. Zyserman (2002), Controlling spatial oscillations in bed level update schemes, Coast. Eng. 46, 2, 109-126, DOI: 10.1016/s03783839(02)00054-6.

Kaczmarek, L.M. (1999), Moveable Sea Bed Boundary Layer and Mechanics of Sediment Transport, IBW PAN, Gdańsk.

Kaczmarek, L.M., J. Biegowski, and R. Ostrowski (2004), Modelling cross-shore intensive sand transport and changes of bed grain size distribution versus field data, Coast. Eng. 51, 5-6, 501-529, DOI: 10.1016/j.coastaleng.2004. 05.007 .

Kaczmarek, L.M., Sz. Sawczyński, and J. Biegowski (2011), Bathymetry changes and sand sorting during silting up of the channels: Part 1 - Conservation of sediment mass, Tech. Sci. 14, 1, 153-170.

Kuroiwa, M., J.W. Kamphuis, T. Kuchiishi, and Y. Matsubara (2004), A 3D morphodynamic model with shoreline change based on quasi-3D nearshore current model. In: Proc. 2nd Int. Conf. "Asian and Pacific Coasts 2003”, 29 February - 4 March 2004, Makuhari, Japan.

Long, W., J.T. Kirby, and Z. Shao (2008), A numerical scheme for morphological bed level calculations, Coast. Eng. 55, 2, 167-180, DOI: 10.1016/ j.coastaleng.2007.09.009.

Moreno, P.A., and F.A. Bombardelli (2012), 3D numerical simulation of particleparticle collisions in saltation mode near stream beds, Acta Geophys. 60, 6, 1661-1688, DOI: 10.2478/s11600-012-0077-x. 
Plumb, R.A. (1979), Eddy fluxes of conserved quantities by small-amplitude waves, J. Atmos. Sci. 36, 9, 1699-1704, DOI: 10.1175/1520-0469(1979)036<1699: EFOCQB $>2.0 . \mathrm{CO} ; 2$.

Pruszak, Z., R. Wierzchnicki, A. Owczarczyk, and R.B. Zeidler (1996), Nearbed sediment concentration from tracer studies, Coast. Eng. Proc. 25, 39013912, DOI: $10.9753 /$ icce.v25.\%25p.

Sawczyński, Sz. (2012), Bathymetry changes and sediment sorting within coastal structures: a case of the silting-up of navigation channels, Ph.D. Thesis, University of Technology, Koszalin, Poland (in Polish).

Sawczyński, Sz., L.M. Kaczmarek, and J. Biegowski (2011), Bathymetry changes and sand sorting during silting up of the channels: Part 2 - Modelling versus laboratory data, Tech. Sci. 14, 2, 171-192.

Struiksma, N., K.W. Olesen, C. Flokstra, and H.J. de Vriend (1985), Bed deformation in curved alluvial channels, J. Hydraul. Res. 23, 1, 57-79, DOI: 10.1080/00221688509499377.

Szymkiewicz, R. (1999), Similarity of kinematic and diffusive waves: a comment on accuracy criteria for linearised diffusion wave flood routing: By K. Bajracharya and D.A. Barry [Journal of Hydrology, vol. 195 (1997), 200-217], J. Hydrol. 216, 3-4, 248-251, DOI: 10.1016/s00221694(98)00276-5.

van Rijn, L.C. (1984), Sediment transport, part I: Bed load transport, J. Hydraul. Eng. 110, 10, 1431-1456, DOI: 10.1061/(ASCE)0733-9429(1984)110:10 (1431).

van Rijn, L.C., R.L. Soulsby, P. Hoekstra, and A.G. Davies (eds.), (2005), SANDPIT, Sand Transport and Morphology of Offshore Mining Pits, Aqua Publications, The Netherlands.

Walstra, D.J.R., T. Chesher, A.G. Davies, J. Ribberink, P. Sergent, P. Silva, G. Vittori, R. Walther, and L.C. van Rijn (2005), Intercomparison of the state of the morphological models. In: L.C. van Rijn, R.L. Soulsby, P. Hoekstra, and A.G. Davies (eds.), SANDPIT, Sand Transport and Morphology of Offshore Mining Pits, Aqua Publications, The Netherlands, AY1-AY23.

Watanabe, A. (1988), Modeling of sediment and beach evolution. In: K. Horikawa (ed.), Nearshore Dynamics and Coastal Processes, University of Tokyo Press, Tokyo, 292-302.

Wiberg, P.L., and J.D. Smith (1985), A theoretical model for saltating grains in water, J. Geophys. Res. 90, C4, 7341-7354, DOI: 10.1029/JC090iC04p07341.

Yalin, M.S., and A.M.F. da Silva (2001), Fluvial Processes, IAHR Monograph, International Association for Hydraulic Research, Delft. 